\title{
Pesquisa em sala de aula no ensino de Biologia: compreensões a partir de uma prática de estágio curricular supervisionado
}

\section{Classroom research in Biology teaching: understandings from a supervised curricular internship practice}

\author{
Robson Leal dos Santos (robsonlealdss@gmail.com) \\ Instituto FederalFarroupilha Campus Panambi \\ Cátia Keske (catia.keske@iffarroupilha.edu.br) \\ Instituto FederalFarroupilha Campus Panambi \\ Carlos Rodrigo Lehn (carlos.lehn@ iffarroupilha.edu.br) \\ Instituto Federal Farroupilha Campus Panambi
}

\section{Resumo:}

O presente artigo contempla um relato de experiência com descrição analítica de uma prática de estágio curricular supervisionado realizado no contexto da formação inicial de professores que teve como objetivo a promoção da pesquisa como princípio pedagógico, como como orientadora das práticas de ensino e de aprendizagem. Realizada na disciplina de Biologia, com uma turma de ensino médio de escola pública no município de Panambi, região Noroeste do Rio Grande do Sul, a prática contou com o desenvolvimento de dois estudos de caso, por meio dos quais abordaram-se as temáticas "fermentação alcóolica" e "crescimento de fungos". Ao buscar provocar o interesse pelo ato de pesquisar nos alunos, dada a compreensão que a pesquisa é um modo de ver o mundo que no contexto educativo constitui-se princípio científico e educativo, reconheceu-se uma participação ativa e, progressivamente, mais autônoma e crítica da turma. Dentre as compreensões tecidas nessa prática, ratificamos a pesquisa como uma alternativa para que alunos e professores signifiquem informações em sala de aula, indo "para além" disso e, assim, produzindo conhecimento.

Palavras-chave: Ensino de Biologia; Estágio curricular; Pesquisa como princípio pedagógico; Professor pesquisador.

\begin{abstract}
:
The present article contemplates an experience report with an analytical description of a supervised curricular internship practice carried out in the context of the initial training of teachers whose objective was to promote research as a pedagogical principle, as a guide for teaching and learning practices. Realized in the discipline of Biology, with a high school class from a public school in the municipality of Panambi, in the Northwest region of Rio Grande do Sul, the practice counted with development of two case studies, through which the themes were addressed "alcoholic fermentation" and "fungal growth". In seeking to provoke interest for the researching act in the students, given the understanding that research is a way of seeing the world that in the educational context constitutes a scientific and educational principle, active and progressively more autonomous and critical participation by the class was recognized. Among the understandings made in this practice, we ratify the research as an alternative for students
\end{abstract}


and teachers to signify information in the classroom, going "beyond" that, and thus producing knowledge.

Keywords: Biology teaching; Curricular internship; Research as a pedagogical principle; Researcher professor.

\section{INTRODUÇÃO}

A contemporaneidade assiste à fluidez de informações, às descobertas científicas e ao progresso técnico. Anunciados como uma das principais características do início de século XXI, os avanços significativos das tecnologias digitais têm acarretado a ascensão de um mundo dominado pelas mídias e redes sociais que fazem a informação circular em escala global e em tempo real. Algumas dessas informações, porém, nem sempre contém cunho científico ou até mesmo sequer correspondem à realidade. Esta "onda" vem se popularizando e a "cultura" de espalhar inverdades também ganhou um termo, as chamadas fake news. Os (des)caminhos dessa cultura não são conhecidos, mas há indícios que ela pode levar, em escala global, a um retrocesso na divulgação de informações equivocadas quanto a ações governamentais, atitudes pessoais, práticas científicas, dentre outras possibilidades que recentemente têm sido evidenciadas.

Em meio a fabulações perversas acerca do dinheiro, da informação (SANTOS, 2010) e das fake news, a sociedade atual vive momento de desinformação. Considerando esse cenário, interessa-nos problematizar as elaborações acerca da informação no contex to educativo da educação básica. Se o ambiente escolar tem como uma de suas funções garantir o acesso à informação, torna-se imprescindível tal problematização, pois por meio dela pode ser possível aos sujeitos compreender a realidade em que vivem, abandonando o "perfil alienado".

Com isso, a educação formal se vê diante da urgência de desenvolver sua função de socialização do conhecimento e da cultura, não limitada à "trans missão" de conteúdos científicos. Fundamentais à formação integral dos sujeitos, os conhecimentos científicos precisam ampliar o olhar dos alunos, com óculos que permita uma visão crítica sobre o contexto global. Tarefa complexa, se considerarmos que o sistema educacional está em crise e que, cada vez mais, adolescentes acreditam ser possível encontrar tudo na internet, desconsiderando que nem todo material vinculado nas diferentes mídias é fundamentado em pesquisa ou que as informações propagadas, em muitos casos, são fonte de manipulação. 
Em meio a esse caos, o conhecimento socializado, sistematizado e produzido n a escola se configura como elemento potencialmente poderoso. Delizoicov, Angotti e Pernambuco (2011) dizem que é fundamental que o saber científico alcance o público escolar para que os sujeitos possam, com isso, ser críticos e questionadores. Contudo, não se pode enfrentar estes novos desafios com as mesmas práticas docentes de décadas anteriores. É preciso entender que hoje os alunos têm um perfil diferente de épocas anteriores, pois possuem outro tipo de socialização, de formas de expressão, de crenças, de valores, de expectativas e de contex to familiar.

Para a mudança de tal contexto, compreende-se a pesquisa como uma alternativa ao contexto pedagógico da sala de aula. Razão pela qual compartilhamo s, na presente produção, uma prática pedagógica desenvolvida no contexto da formação inicial de professores. A intenção é ratificar a possibilidade e a necessidade da pesquisa se fazer mais presente no itinerário formativo, tanto de professores como de alunos. Além disso, buscamos desmistificar o uso da pesquisa em sala de aula, com o intuito de aproximar o conhecimento científico ao conhecimento cotidiano, problematizando ambos e contribuindo na formação crítica do sujeito.

\section{PESQUISA EM SALA DE AULA - COMPREENSÕES TEÓRICAS SOBRE OS PROCESSOS DE ENSINAR E DE APRENDER}

A valorização da pesquisa na formação dos professores é recente, mas a questão do professor-pesquisador tem recebido uma atenção crescente, acentuada nos últimos tempos. Como destacado por Lüdke (2001), Stenhouse em 1975 reivindicava para o professor, numa bela metáfora, a mesma situação do artista, que ensaia com seus diferentes materiais as melhores soluções para os problemas de criação (STENHOUSE, 1975 apud LÜDKE, 2001). A esse encontro, Dickel (1998) defende a pesquis a como “possibilidade de o professor tomar a si o direito pela direção de seu trabalho e, comprometendo-se com a busca de uma sociedade justa, torná-lo capaz de provocar em seus alunos a capacidade de inventar um mundo alternativo" (DICKEL, 1998, p. 33-34). Mas, como convidam a pensar Lüdke, Cruz e Boing (2009, p. 455), "o que conta como pesquisa?".

Conforme os autores, "a possibilidade de um professor de escola de educação básica realizar pesquisa é algo que vem suscitando significativo debate no meio universitário, mais até do que no contexto de atuação desse professor" (LÜDKE; 
CRUZ; BOING; 2009, p. 456). Existe, entretanto, uma distância entre escola e academia, o que permite a configuração de formas e visões diferenciadas de trabalho. Porém, as questões referentes à conceitualização se restringem apenas a uma dessas duas instâncias: as instituições de ensino superior. Contudo, "é preciso lembrar a importância que a prática de pesquisa pelo professor confere ao conhecimento por ele produzido"(ibidem, p. 466).

Um pesquisador estabelece ligações entre diferentes conceitos para evidenciar e apoiar uma questão de pesquisa. O contexto para constituição desse perfil, no entan to, não pode ser "um meio que despreze o professor como produtor de conhecimento" (DICKEL, 1998, p. 51). Do contrário, precisa provocar o professor a criar hipóteses, fazer experimentações referentes à sua prática educativa, proporcionando a formulação de teorias.

Mas isso não soa distante da realidade escolar? Lüdke (2001), em estudo sobre o saber e a pesquisa do professor de Educação Básica, identifica uma variedade de noções entre os professores participantes. Ao interrogá-los sobre o que consideravam como pesquisa, chamam atenção ideias como “[...] "mas essa pesquisa feita lá (na academia) não é aquela que serve para nós aqui, para nossos problemas. Eles (da academia) deveriam vir até aqui, para ver o que é preciso estudar. Isto é um verdadeiro laboratorio" (LÜDKE, 2001, p. 89). Essa dualidade de perspectivas, para a autora, revela no docente o entendimento de que a pesquisa acadêmica não alcança os problemas "e os temas mais importantes e próximos do seu trabalho na escola, mas que ela provavelmente domina os métodos e os recursos necessários para investigar devidamente aqueles assuntos fundamentais" (ibidem, p. 89). Contudo, como conclui

\begin{abstract}
[...] há professores desenvolvendo a chamada pesquisa a cadêmica em nossa s escola s. Por outro lado, a pesquisa típica da universidade teria muito a ganhar com a a ceitação de umanova conceituação da pesquisa do professor, que the conferisse estatuto epistemológico legítimo, ajudando assim a própria universidade a ampliar seus horizontes de pesquisa, envolvendo temas e abordagens metodológicas mais próximos dos problemas vividos por alu nos e professores, podendo assim contribuir de forma mais efetiva para o desenvolvimento do sa ber docente (LÜDKE, 2001, p. 92-93).
\end{abstract}

Se estamos no caminho de aproximações entre a natureza da pesquisa acadêmica e a pesquisa na sala de aula da educação básica, nos valemos de Dickel (1998, p. 34) quando deseja "que o pessimismo da teoria nos seja leve" (p. 34). A identidade como pesquisador dos professores da educação básica, embora muito retraída, confere, 
sobretudo, pontos positivos, como a reflexividade no trabalho do profes sor. Por outro lado, evidencia dificuldades no desenvolvimento dessa prática: a falta de preparação adequada dos professores para o bom desempenho em pesquisa, resultados considerados menos rigorosos do que os feitos pelo âmbito acadêmico; e a falta de tempo disponível para que o professor se dedique a essa prática (ZEICHNER; NOFKE, 2001 apud LÜDKE: CRUZ, BARRETO, 2009).

Relativizando essa tensão, Freire (1996) contribui ao defender que a inda gação, a busca e a pesquisa fazem parte da natureza da prática docente. Em suas palavras: "o que há de pesquisador no professor não é uma qualidade ou uma forma de ser ou de atuar que se acrescente à de ensinar. [...] O de que se precisa é que, em sua formação permanente, o professor se perceba e se assuma, porque professor, como pesquisador" (FREIRE, 1996, p. 15).

Nesse sentido, a pesquisa pode ser compreendida como uma "postura filosófica" (FREIRE, 1996), constituir-se em princípio pedagógico, como orientadora das práticas de ensino e de aprendizagem e tem como objetivo desenvolver a “curiosidade em direção ao mundo que o cerca, gera inquietude, possibilitan do que o estudante possa ser protagonista na busca de informações e de saberes, que sejam de senso comum, escolares ou científicos" (BRASIL, 2011, p. 22). Para Demo (2002, p. $360)$,

\begin{abstract}
A influência quea/o professora/professor exerce deve po der libertar, não apequenar. Para tanto, atividades como pesquisa e elaboração própria parecem ser decisivas. Observando de perto, porém, este contexto está marcado profundamente pelo cuidadom e todoló gico. À medida que a/o a luna/alunoé levado a 'fazer' conhecimento, sain do da posição de quem a penas a dquire, recebe pela via da reprodução, a prende a preocupar-se com metodologia científica. Resultado mais fundamental disso pode ser que comece a diferenciar níveis distintos de qualidade do conhecimento disponível, teorias mais e menos consistentes, táticas mais e menos sustentáveis de produçãoe tratamentode dados, elaborações mais e menos origina is dentro das polêmicas vigentes.
\end{abstract}

Ao encontro desse "cuidado metodológico" que pode emergir no deslocamento do aluno em direção a uma postura de "fazer conhecimento" proposto por Demo (2002), a questão que parece ser essencial ao professor é entender o contexto no qual a pesquisa na educação básica se desenvolve/pode ser desenvolvida.

\title{
3. CONTEXTO DA PRÁTICA
}


Situada no contexto das práticas profissionais de Estágio Curricular Supervisionado de Licenciatura em Ciências Biológicas do Instituto Federal Farroupilha - Campus Panambi, a experiência aqui proposta ocorreu no oitavo e último semestre do curso. Ocupando-se do ensino de Biologia no Ensino Médio, a prática foi desenvolvida junto a uma turma de $1^{\circ}$ ano, do turno da noite, composta por 26 alunos, cuja faixa etária era em torno de 16 anos. A média de presentes por aula era, contudo, de 16 (dezesseis) alunos, o que evidencia uma característica da maioria deles, identificada intencionalmente no momento do (re)conhecimento do perfil da turma realizado anteriormente à regência na referida etapa da educação básica.

Abordando conceitos relativos à fungos e fermentação, o Plano de Ensino planejado, desenvolvido e analisado crítica e reflexivamente, contou com a proposição de dois Estudos de Caso, sendo esse o procedimento metodológico adotado para o ensino de Biologia na experiência relatada. Queiroz e Cabral (2016, p. 13) destacam que "no Brasil, especialmente no ensino de ciências, tem se destacado a aplicação do método de Estudo de Caso, cuja difusão se intensifica a partir do início dos anos 2000”, e o qual é um variante do método de Aprendizagem Baseada em Problemas (ABP), da língua inglesa Problem Based Learning (PBL). A intenção foi provocar nos alunos a assunção de uma postura ativa no processo de aprendizagem, aproximando-os de problemas reais do dia-a-dia, em especial quanto ao desenvolvimento de fungos em alimentos.

Ao encontro dos indicativos de Stecanela e Williamson (2013), atentou-se para o uso pedagógico da pesquisa em sala de aula concebida como princípio educativo, buscando inverter a lógica organizativa do trabalho escolar tradicional, (re) conhecer e considerar os saberes prévios, as inquietações e curiosidades dos alunos e, em aproximações reconstrutivas, transitar pelo conhecimento formal sistematizado pela humanidade. Assim, a definição de uma problematização sobre fungos e fermentação alcoólica teve como referência, indicativos informais dos alunos em momento anterior à regência, quando o Professor Estagiário observou aulas da turma com a professora responsável pela disciplina de Biologia: reclamações sobre a saúde e interesse sobre condições normais x patológica. Na sequência, buscou-se relacionar esse interesse a uma forma, um jeito diferente que permitisse "aproximações reconstrutivas no trân sito com o conhecimento formal". 
De modo geral, a prática desenvolvida contou com um total de 20 horas-aula (20 períodos de 50 minutos cada um) e foi organizada em três momentos. No primeiro deles, o Professor Estagiário desenvolveu uma aula prática com os alunos sobre fermentação alcoólica, abordando-a quanto ao processo biológico, à importância das leveduras para tal, bem como seus diversos usos. Num segundo momento, explicou-se a proposta de trabalho, enfatizando as contribuições da PBL aos processos de ensino e aprendizagem. Nessa etapa, desenvolveu-se o Estudo de Caso "Pão caseiro x Pão industrializado". Por fim, fez-se uma síntese coletiva da experiência, cujos in dicativ os são descritos e analisados também na sequência do texto.

Vale destacar que, para complementar as atividades práticas desenvolvidas, e na perspectiva de identificar o que os alunos, sujeitos participantes da prática aqui analisada, entendiam por "pesquisar" e "pesquisa" no contex to educativo, elaborou -se um questionário com algumas perguntas discursivas e outras objetivas, cujos dados produzidos são apresentados na sequência do texto. $O$ intuito não foi pressupor o entendimento daquele grupo de adolescentes e sim buscar saber sobre com eles. Não poderia ser diferente se considerarmos que assumir a postura de pesquisar é entender que tal ato é muito mais que teclar botões e ler, trata-se de um modo de compreensão da realidade, produzindo e fortalecendo argumentos que ampliam a capacidade de explicar e compreender fenômenos (MORAES; LIMA, 2004).

Com a intenção de desmitificar a percepção inicial, as questões tratavam sobre o que se entende por pesquisa, sobre por que pesquisar, por quais meios pesquisar, com que frequência e sobre quais assuntos. Para fins de preservar a identidade, os alunos foram nominados como P1 até P19, na referência de Participante 1 à Participante 19 tanto nos momentos em que refere-se respostas ao questionário, como quando nomeia se falas registradas pelo Professor-Estagiário ao final de cada Plano de Aula, ao refle tir sobre os processos de ensino e aprendizagem.

\subsection{ATIVIDADE PRÁTICA “O QUE É FERMENTAÇÃO ALCÓOLICA?"}

Com o objetivo de compreender a fermentação alcoólica como o processo no qual, açúcares são transformados em energia, com produção de etanol e gás carbônico, caracterizada como anaeróbica - por sua ocorrência sem a presença de oxigênio, para 
desenvolver a atividade em perspectiva prática os alunos foram levados para o laboratório de Ciências da escola.

Neste primeiro momento de interação tanto entre professor-aluno quanto professor estagiário-alunos no espaço laboratório e em atividade prática, o Professor Estagiário valeu-se de um roteiro para que os alunos conseguissem organizar-se e entender todos os passos que estavam sendo desenvolvidos e analisados. Buscou-se relacionar a fermentação alcoólica como o tipo de fermentação responsável pela produção da cerveja e do pão. Isso só acontece pela ação de fungos, mais especificamente, leveduras, como a Saccharomyces cerevisae, estudada no caso em questão.

Para a realização da prática, foram preparados três erlenmeyers com condições diferentes, todos vedados com um balão para ver o funcionamento do processo: ASolução de Leveduras; B- Solução de Leveduras + açúcar + banho de gelo; C- Solução de Leveduras + açúcar + banho maria.

Após cinco minutos, os alunos teriam que observar se em algum dos três casos havia ocorrido a fermentação (Figuras 1 e 2) e responder às seguintes questões: por que a fermentação ocorreu em um e em outro não? Quais são os fatores imprescindíveis para que a fermentação ocorra?

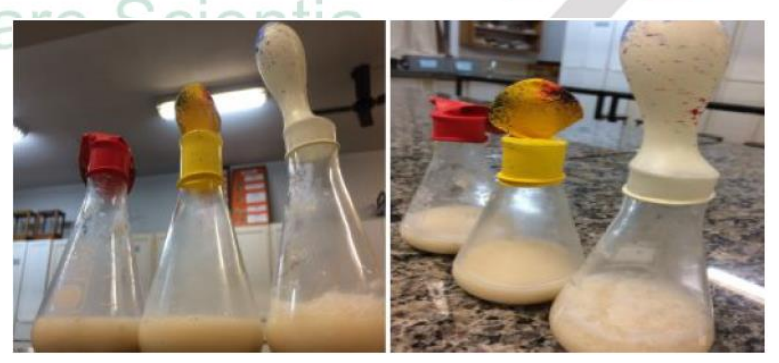

Figuras 1 e 2: Prática de fermentação alcoolica.

Foram feitos alguns questionamentos aos alunos visando problematizar as percepções que foram sendo compartilhadas conforme iam debaten do e pesquis an do sobre o tema na internet, fazendo uso de seus aparelhos celulares.

$\mathrm{Na}$ análise reflexiva deste primeiro encontro da prática de Estágio Curricular Supervisionado IV - parte do planejamento de cada uma das aulas -, o Professor Estagiário indicou que em poucos minutos de observação os alunos haviam percebido que o balão do tratamento "C" havia enchido, a exemplo das frases de P18 e P9, 
respectivamente: "Professor aquele ali já encheu, tá pronto", "O balão ali na água moma subiu". Tais percepções foram problematizadas inicialmente com o questionamento sobre o porquê de o balão subir. Contudo, os alunos não haviam relacionado a re lação fermentação alcoólica - liberação do gás dióxido de carbono. Foi o diálogo estabelecido que permitiu a compreensão da fermentação evidenciada por perguntas como: "quer dizer que se eu tomar esse líquido, eu vou ingerir álcool?" e "Profe ssor, está fazendo bebidas alcoólicas na escola?” feitas por P12 e P11.

Reconhecida a produção de etanol no processo, indicando que haviam compreendido a relação da formação de seus produtos, o Professor Estagiário provocou os alunos a criarem hipóteses dos casos "A" e "B". Depois de alguns momentos de dispersão (provavelmente pela postura habitual e/ou confortável de manter-se aluno "receptor" em um processo de transmissão de conhecimento, resquício da tendência tradicional de ensino), a turma apresentou hipóteses como "o gelo não deixa a levedura agir" (P3) e "sem açúcar, não tem no que ela agir" em relação a ação da levedura, bem como chegou coletivamente a afirmação que "a temperatura interfere sim no processo" (P1).

As problematizações feitas sobre o quê e o porquê aconteceu o processo de fermentação desencadeou diálogo entre os alunos. Independentemente das hipóteses que tinham, aos poucos, foram sentindo-se "dispostos" a compartilhar. E este processo envolveu professor e aluno, o primeiro desafiando o segundo, que não é visto como objeto de ensino, mas, sim, como sujeito do processo e integrante ativo ness a postura, convertendo a pesquisa numa atitude cotidiana que possibilita o pensamento construtivo (DEMO, 2007).

No momento posterior à sala de aula, o pensar sobre o que nela aconteceu e porque desta ou daquela forma ocorreu junto aos profes sores formadores orientadores da prática de estágio, permitiu ainda uma outra compreensão: a importância do diálogo e da problematização. Como destacam Zanon e Kierepka (2019), o diálogo possibilita a vivência de atitudes reflexivas e a reflexão crítica compartilhada possibilita o reconhecimento e enfrentamento de problemas da prática docente. Para as autoras, "a problematização da prática e teorias possibilitam o reconhecimento e enfrentamen to de problemas da própria prática docente, que é um processo necessário para a transformação das ações docentes”(ZANON; KIEREPKA, 2019, p. 18). 


\subsection{ESTUDO DE CASO "PÃO CASEIRO X PÃO INDUSTRIALIZADO"}

Desenvolvido a partir de um experimento de comparação entre o crescimento fúngico em pães caseiros e pães industrializados, o Estudo de Caso foi proposto de forma que os alunos pudessem perceber a diferença entre dois tratamentos em amostras do alimento pão. Inicialmente foram feitos questionamentos sobre o conhecimento sobre fungos em alimentos e os problemas decorrentes disso, depois, destacou-se o grande consumo do alimento estudado pelas pessoas da região e do mundo, os benefícios e malefícios a ele atribuído no senso comum, problematizando a necessidade da sua ingestão diariamente ou não.

Na sequência, propôs-se outra atividade prática, desta vez envolvendo duas amostras de pão caseiro e duas de pão industrializado, ocasião em que foram colocados individualmente em embalagens plásticas junto a guardanapos úmidos. Em uma amostra de cada tipo de pão envolvido no experimento colocou-se mel sobre a superfície da porção. As amostras foram nominadas A, B, C e D, sendo: A - Pão caseiro sem mel; B - Pão caseiro com mel; C - Pão industrializado sem mel; D - Pão industrializado com mel.

Desta vez, os alunos foram orientados a desenvolver a atividade em suas casas. Para registro do acompanhamento do processo, receberam uma ficha que continha breve descrição da atividade e questionamentos a serem respondidos que vão ao en contro de uma PBL: Quatro pães, dois deles caseiros e outros dois industrializados. Dois tratamentos, um com adição de mel, outro sem adição de mel. Em duas amostras, u ma porção de pão caseiro e uma porção de pão industrializado, foi adicionado mel. As quatro amostras são embaladas individualmente e observadas por 10 dias. O que acontece? Por que acontece? Qual a ação do mel? Orientou-se, sobretudo, que as quatro embalagens com os referidos tratamentos fossem colocadas em locais de uso comum no dia-a-dia do funcionamento de uma casa, como por exemplo, a parte superior da geladeira, sobre a mesa das refeições, entre outros, sendo que a maioria dos alunos optou pela primeira sugestão.

Durante os 10 dias houve acompanhamento do material nos dias 2 e 4, para ver se o experimento estava seguindo como se esperava. Nas Figuras 3 e 4, na sequência, é 
possível visualizar o crescimento de fungos nos diferentes tratamentos de um grupo de amostras.
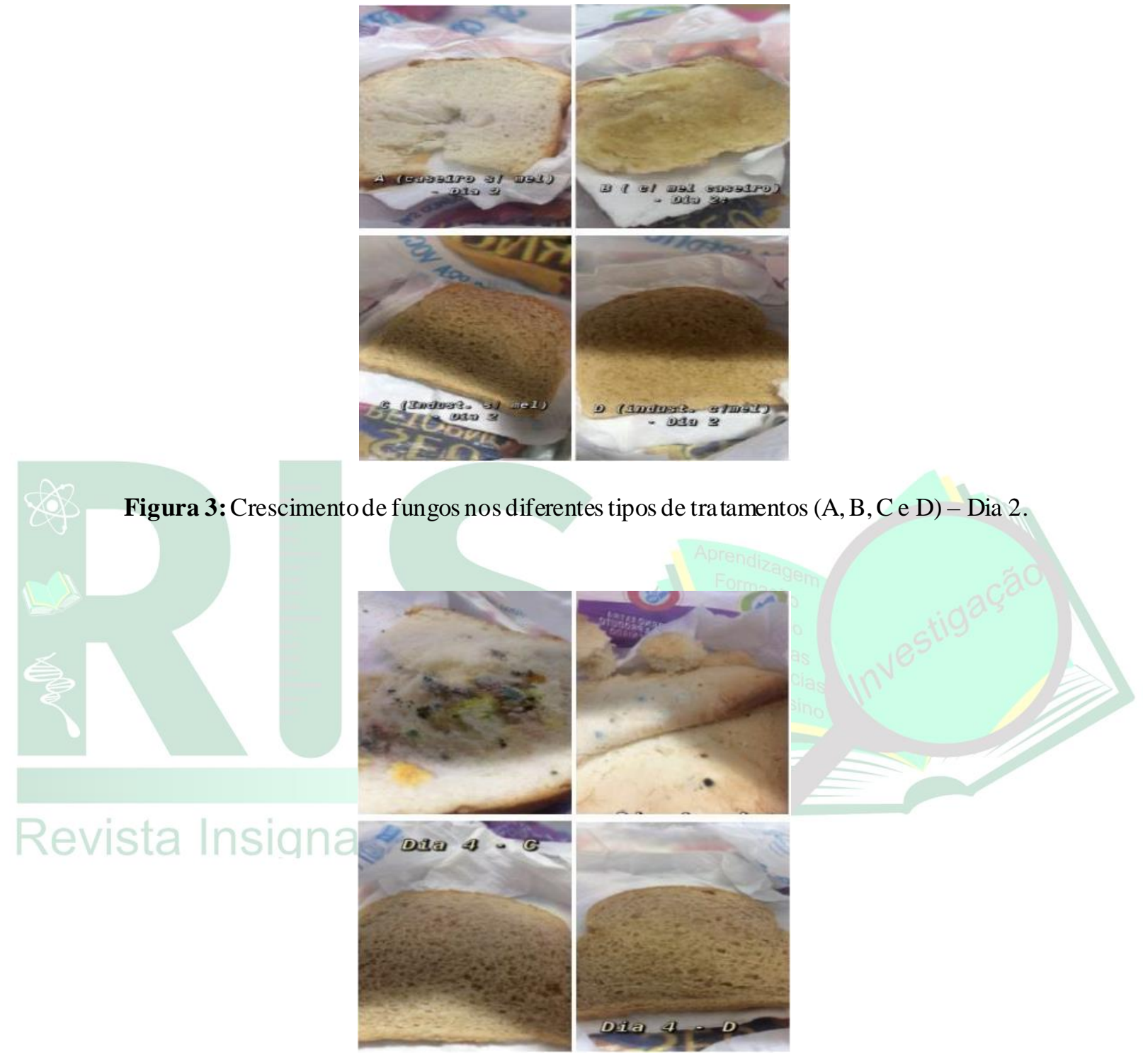

Figura 4: Crescimento de fungos nos diferentes tratamentos (A, B, C e D) - Dia 4.

Ao décimo dia, os pães foram levados para a aula e compartilharam-se as hipóteses sobre o porquê de alguns pães estarem mais contaminados que outros. Para guiar os alunos, foi entregue uma ficha de orientação do Estudo de Caso. O que se esperava desse experimento? A intenção era verificar as propriedades antifúngicas que o mel apresenta, o porquê disso acontecer e a constatação das condições nas quais fungos desenvolvem-se. Os alunos puderam socializar e discutir suas ideias, tanto com o professor quanto com os colegas em sala, sendo que alguns haviam interpretado 
erroneamente a presença do mel no experimento. Pela propriedade intrínseca aos alimentos que contém açúcar, a "doçura" do mel foi interpretada como fator que "atrairia" mais fungos para o pão. O que há de errado com isso? Pode até ser que os alunos erraram o sentido, mas quer dizer que criaram uma hipótese baseada no que eles conheciam, sendo autônomos, mobilizaram seus saberes do senso comum, ampliandoos e ressignificando, em postura de pesquisa. Posteriormente, cumprindo com sua responsabilidade no processo de mediação, o Professor Estagiário indicou que não era acertada essa concepção, já que o propósito do mel era contrário a tal hipótese.

\section{DISCUSSÃO DOS DADOS}

Os dados produzidos por meio do questionário, permitiram o reconhecimento do entendimento da turma sobre "pesquisar" e "pesquisa" no contexto educativo. Estariam os alunos fazendo uso da pesquisa em sentido amplo que promove o acesso ao conhecimento ou estariam valendo-se do seu sentido restrito de " $C t r l C+C t r l ~ V$ ", prática que parece ser cristalizada pelos adolescentes como exercício da pesquisa na educação básica?

Dentre as respostas compartilhadas pelos alunos, a pesquisa como uma metodologia para saber mais sobre algo foi entendimento recorrente. "Entendo que a pesquisa é um método de saber mais" relatou P10, assim como de forma próxima, P8, P5, P2. P9 entende a pesquisa como "algo para argumentar nosso con hecimento, com exemplos para entender melhor", concepção que podemos teorizar com o argumento de Moraes e Lima (2004) que dizem que a pesquisa em sala de aula proporciona um avançar na compreensão da realidade, produzindo e fortalecendo argumentos.

Já P11 relata que pesquisar é "procurar algo interessante". As duas atividades práticas que foram propostas na prática de estágio foram algo interessante, dada sua correlação a preocupações com a saúde. Para além disso, em nosso ponto de vista, as atividades envolvidas no Estudo de caso "tiraram" a turma e o professor da comodidade. Isso porque a exigência de estudar sobre os conceitos que abordou e que balizaram as discussões sobre as hipóteses dos alunos, fez com que o Professor Estagiário se lançasse à experimentar em sua sala de aula, tal como num laboratório, uma alternativa entendida no momento como a "melhor maneira de atingir seus alunos, no processo de ensino/aprendizagem" (LÜDKE, 2001). Os alunos, ao compararem amostras, precisaram pensar de forma independente suas hipóteses, aproximando conhecimentos 
que já possuíam àqueles científicos que estavam sendo estudados. Vale destacar ainda que, ao observar que o pão caseiro, tanto na amostra $\mathrm{A}$ quanto na $\mathrm{B}$, te ve maior suscetibilidade ao desenvolvimento de fungos, os alunos foram levados a reconhecer o que aconteceria "normalmente" com um pão, uma vez que os industrializados, amostras $\mathrm{C}$ e D, não apresentaram igual contaminação. Os alunos chegaram a um questionamento que pode fazer de um conhecimento científico sistematizado pela escola um conhecimento significado em seu dia-a-dia: "Imagina a quantia desses produtos conservantes que eles usam?", nas palavras de P5. Os receios subjacentes a essa hipótese suscitam outras questões, como a veracidade das informações fornecidas nas embalagens de pão industrializado.

Contudo, não foi tarefa fácil os alunos responsabilizarem-se pela observação, análise, elaboração de hipóteses e síntese coletiva de forma a exercer sua au tonomia. Conforme Kuhn e Zilli (2015), a pesquisa como proposta metodológica faz o aluno conhecer seu próprio processo de aprender, tornando-o mais autônomo (KUHN; ZILLI, 2015). Silva (2013) salienta:

Potencializar o fortalecimento da relação entre o en sin o e a pesquisa, na perspectiva de contribuir com a edificação da a uto nomia in tele ctual dos sujeitos frente à (re)construção do conhecimento e de outras práticas sociais. Isso significa contribuir, entre outros aspectos, para o desen volv imen to das capacidades de, a o longo da vida, interpretar, analisar, criticar, refletir, rejeitar ideias fechadas, a prender, buscar soluções e propor alternativas, potencializadas pela investigação e pela responsabilid a de ét ica a s sumid a diante das questões políticas, sociais, culturais e econômicas (SILVA, 2013, p. 76).

Ao propor o Estudo de Caso "Pão caseiro x pão industrializado", a intenção foi de valorizar a pesquisa e a busca por respostas para questões cotidianas para além do filtro da internet. Ao analisarmos, porém, uma crescente participação em sala de aula durante o período de regência, dado que no início a turma tinha apresentado certa resistência e alguns alunos não se sentiram muito à vontade com e/ou dispuseram-se à proposta até sua conclusão, o sentimento foi de aventurar-se à pesquisa, pela pesquisa e com ela ensinar. Talvez não com a vigilância epistemológica necessária, mas certamente ao encontro dela. Talvez sem conseguir ser "o guardião das competências mínimas a serem desenvolvidas, numa relação ética e política com as três dimensões do conteúdo - conceitual, atitudinal e procedimental - na busca de um equilíbrio nos investimentos didático-pedagógicos entre todas", como propõem Stecanela e Williamson (2013, p. 291). Mas com o sentimento de ter elaborado hipóteses sobre a 
melhor forma de ensinar, repensando-as à medida que os questionamentos sobre o porquê desse ou daquele pressuposto foram escolhidos como a melhor forma de ensinar.

A respeito do motivo que leva os alunos a pesquisarem, segundo P5, P12, P13 e P15, buscar conhecimento é a motivação. Também nesse sentido, P18 e P19 responderam que pesquisam quando estão com dúvidas ou com necessidade de buscar certas informações, enquanto P1, P3, P11 e P14 afirmam que pesquisam por seus próprios interesses. A definição de "próprios interesses" pode indicar diferentes questões, desde um desinteresse ao que é trabalhado na escola, até mesmo, contrariamente, uma postura de ir além daquilo que é abordado pelo professor. Conforme Demo (2007) destaca:

É equívoco fantástico imaginarque o 'contato pedagógico' se estabeleça em a mbiente de repasse e cópia, ou na rela ção aviltada de u m su jeito copia do (professor, no fundo também objeto, se apenas ensina a copiar) dia nte de u m objeto a penas receptivo (aluno), condenado a escutar au las, tomar notas, decorar, e fazer prova (DEMO, 2007, p. 7).

Para reverter esse paradigma negativo que é recorrente na educação básica, é, segundo Becker (2007), necessário mostrar que a sala de aula também é um local de pesquisa. Para além disso, como faz pensar Wenzel (2019) ao defender a prática da pesquisa na formação inicial de professores, é importante "ensinar a fazer pesquisa, pois, ninguém nasce sendo pesquisador, fazer pesquisa não está atribuída à uma herança genética." (WENZEL, 2019, p. 183). O estudo de caso em questão buscou propor e mostrar que todos podem ser pesquisadores e reconhecer a pesquisa como um princípio pelo qual podem, continuamente, aprender e ensinar aos seus colegas e familiares. O mel, parte dos hábitos alimentares de muitas famílias na região, foi u sado como ponto de intersecção entre os conhecimentos cotidianos e suas propriedades antifúngicas. Entender observando e elaborando hipóteses de que tais propriedades são benéficas para o pão e desfavoráveis para os fungos, configura uma saída da postura de “objeto apenas receptivo".

Resgatando movimentos recentes de reestruturação curricular do Ensino Médio no Rio Grande do Sul, é possível destacar a proposição da pesquisa como "estratégia metodológica estruturada que possibilita a construção de novos conhecimentos e a formação de sujeitos pesquisadores, críticos e reflexivos" (RIO GRANDE DO SUL, 2011-2014, p. 21). 
Referente a questão de frequência com que pesquisam e a fonte que usam, a maioria indicou buscar informações na internet mais que três vezes ao dia, sendo que nenhum deles tem o hábito de não se valer diariamente de tal recurso ao menos uma vez por dia. Dentre os principais tópicos que eles pesquisam destacam-se: entretenimento, educação, ciência e outros - como "fofoca" citada por P10 e P17. Indicativos esses que ratificam a necessidade do professor pesquisador privilegiar o espaço de dúvidas e perguntas, indagando e problematizando os fenômenos da realidade (BECKER, 2007), convidando seus alunos a não manterem-se receptivos a toda e qualquer informação, de forma inclusive alienada.

Uma ação desprovida de uma questão problematizadora, de objetivos, intencionalidade, isenta de percurso metodológico (inclusive cuidadoso, como sugere Demo, 2007) e da busca por resultados, bem como sem a elaboração de "conclusõ es", não contribui para que o aluno reconheça o potencial formativo da pesquisa. Os interesses dos alunos são, nesse processo, essenciais. Segundo Jélvez (2013, p. 127), o estudante deve ser reconhecido e respeitado pela escola, por educadores e com unidade na escolha e concretização de seus projetos e, conforme destacam Kuhn e Zilli (2015), a pesquisa como princípio pedagógico orientador da aprendizagem oportuniza que ele se torne sujeito de suas aprendizagens, adquirindo também protagonismo.

Para esse protagonismo ao aprender, é essencial protagonismo ao ensinar e, como destacam Pimenta e Lima (2004, p. 62), apesar da identidade do professor ser construída ao longo de sua trajetória como profissional do magistério, "é no processo de sua formação que são consolidadas as opções e intenções da profis são que o curso se propõe a legitimar”. Daí a importância do trabalho com a pesquisa no estágio, do uso dela pelo estagiário para aprender e para ensinar, dando corpo ao estágio como pesquisa, como sugerem as autoras. Para tanto, o trânsito entre a universidade e as escolas nos momentos dos estágios é fundamental (PIMENTA: LIMA, 2004).

$\mathrm{Na}$ esteira das autoras, vale destacar ainda que entre as concepções tradicionais de estágio (como imitação de modelos ou como instrumentalização técnica) e o e stá gio como pesquisa, há diferenças de possibilidades de atuação: enquanto as primeiras, baseadas na fórmula observação-participação e regência numa concepção de que se aprende a ser professor a partir da imitação de práticas observadas, não trazem melhorias para os resultados de ensino e não conseguem formar um profissional reflexivo; a segunda permite o fazer pesquisa (PIMENTA; LIMA, 2004). Nessa 
concepção de formação mais ampliada, o ensino é compreendido como atividade complexa e o professor como produtor de conhecimentos sobre o ensinar, e não mero reprodutor de técnicas observadas, colocando-o no exercício da reflexão e da pesquisa sobre a prática. Trate-se assim, de desenvolver o estágio como atividade teórica instrumentalizadora da práxis, compreendendo o professor em formação inicial - do estagiário, futuro professor - como intelectual em processo de formação e a educação como um processo dialético do homem historicamente situado, concepção que leva ao entendimento do estágio como uma "investigação das práticas pedagógicas nas instituições educativas" (PIMENTA; LIMA, 2004, p. 47).

Tornar a pesquisa como prática educativa (PIMENTA, 2012), é um desafio que tem sido reconhecido e abordado nos estágios curriculares da Instituição, não sendo, porém, uma tarefa simples ao Professor-Estagiário pensar sobre sua prática. Contudo, não há como deixar de evidenciar que as práticas de ensino e aprendizagem nesse tex to apresentados, permitiram o trabalho de aspectos inerentes à construção da identidade profissional, aos saberes e às posturas específicas ao exercício profissional docente, como destacam Pimenta e Lima (2004), no contexto da Licenciatura em Ciências Biológicas do IFFar.

\section{CONSIDERAÇÕES FINAIS}

$\mathrm{Na}$ experiência aqui relatada, a pesquisa surge como uma alternativa em uma prática pedagógica no contexto da formação inicial de professores. A análise do seu desenvolvimento, porém, indica para além de uma postura docente que "viabiliza" o processo de ensino. A proposição de pensar um problema comum nos alimentos, o desenvolvimento de fungos em pães, nos faz crer que os alunos envolvidos não só significaram conceitos abordados como fungos, leveduras, fermentação alcoólica, mas que, mesmo depois de encerrada a regência do Professor Estagiário e/ou da conclusão do $1^{\circ}$ ano do Ensino Médio, terão postura diferente ao interagir com as informações vinculadas junto à produtos alimentícios.

Na esteira do ditado popular "uma andorinha só não faz verão", compreendemos que práticas isoladas como essa não tornam a pesquisa prática em sala de aula. Contudo, ao encontro do que destacam Lüdke (2001) e Freire (1996), há nas escolas de educação básica tantas outras práticas e ações que vão ao encontro do exercício da pesquisa como 
postura docente e como possível postura discente para aprender. Não basta, porém, a ideia de um professor pesquisador. Conhecer e aprender pela pesquisa implica reconhecê-la como postura que permite aos alunos elaborarem suas hipóteses, aproximando-as e relacionando-as aos conhecimentos científicos, assumindo seu protagonismo ao aprender.

No contexto educativo, uma das principais alternativas pode ser o desenvolvimento de práticas pedagógicas não limitadas às questões de tran s missão de conteúdos científicos, mas, sim, que objetivem ampliar a visão do aluno como corresponsável pelos processos de ensino e de aprendizagem. Esse artigo é mais que apenas um incentivo à pesquisa. De fato, objetivamos isso também, mas o que compreendemos aqui é que a postura de pesquisador pode ser "estimulada" na formação inicial de professores. Contudo, temos ciência que a pesquisa como princípio pedagógico precisa ser desmistificada no contexto da formação continuada, de forma que o docente se reconheça como professor pesquisador e, assim se vendo, provoque no aluno o desenvolvimento de um jeito diferente de entender os conhecimentos "da escola".

\section{REFERÊNCIAS}

BECKER, F. Ensino e pesquisa: qual a relação? In.: BECKER, F.; MARQUES, T. B. I. (Org.). Ser professor é ser pesquisador. Porto Alegre: Mediação, 2007.p. 11-20.

BRASIL. Parecer CNE/CEB n⿳05 de 04 de maio de 2011. Diretrizes Curriculares Nacionais para o Ensino Médio. Brasília: CNE/CEB, 2011. Disponível em $<$ http://portal.mec.gov.br/index.php?option=com_docman\&view=download\&alias $=801$ 6-pceb005-11\&category_slug=maio-2011-pdf\&Itemid=30192> Acesso em: 24 set. 2020 .

DEMO, P. Educar pela pesquisa. Campinas: Autores Associados, 2007.

DEMO, P. Cuidado Metodológico: signo crucial da qualidade. Sociedade e Estado, Brasília, v. 17, n. 2, p. 333-348-126, jul./dez. 2002.

DELIZOICOV, D.; ANGOTTI, J. A.; PERNAMBUCO, M. M. Ensino de Ciências: fundamentos e métodos. 4. ed. São Paulo: Cortez, 2011. (Coleção Docência em Formação).

DICKEL, A. Que sentido há em se falar em professor-pesquisador no contexto atual? Contribuições para o debate. In.: GERALDI, C.; FIORENTINI, D.; PEREIRA, E.M.A. (Orgs.). Cartografias do trabalho docente. Campinas: Mercado de Letras, 1998. p. 3371. 
FREIRE, P. Pedagogia da Autonomia: Saberes Necessários à Prática Educativa. 25. ed. São Paulo: Paz e Terra, 1996.

JÉLVEZ, J. A. Q. A pesquisa como princípio pedagógico no Ensino Médio. In.: AZEVEDO, J. C.; REIS, J. T. Reestruturação do Ensino Médio. São Paulo: Fundação Santillana, 2013. p. 117-138.

KUHN, M.; ZILLI, G. T. S. A Pesquisa como Princípio Pedagógico: Protagonismo e Interdisciplinaridade. In.: CALLAI, H. C.; TOSO, C. E. I. (Org.). Diálogos com professores. Ijuí: Ed. Unijuí, 2015. p. 79-100.

LÜDKE, M. O professor, seu saber e sua pesquisa. Educação e Sociedade, ano XXII, n. 74, p. 77-96, abril/2001.

LÜDKE, M.; CRUZ, G. B. C.; BOING, L. A. A pesquisa do professor da educação básica em questão. Revista Brasileira de Educação, v. 14, n. 42, p. 466-602, set./dez. 2009.

MORAES, R.; LIMA, V. M. R. Pesquisa em sala de aula: tendências para a educação em novos tempos. Porto Alegre: Edipucrs, 2004.

PIMENTA, S. G.; LIMA, M. S. L. Estágio: diferentes concepções. In: Estágio e docência. São Paulo: Cortez, 2004. p. 33-57.

PIMENTA, S. G. Saberes pedagógicos e atividade docente. 8. ed. São Paulo: Cortez, 2012.

QUEIROZ, S. L.; CABRAL, P. F. O. Ensinar e aprender ciências na educação básica a partir de estudos de caso. In.: QUEIROZ, S. L.; CABRAL, P. F. Estudos de Caso no Ensino de Ciências Naturais. São Paulo: Art Point Gráfica e Editora, 2016. p. 11-19.

RIO GRANDE DO SUL. Secretaria da Educação. Proposta pedagógica para o Ensino Médio politécnico e educação profissional integrada ao Ensino Médio - 2011-2014. Porto Alegre: Governo do Rio Grande do Sul, Secretaria da Educação, nov. de 2011. Disponível em <https://servicos.educacao.rs.gov.br/dados/ens_med_proposta.pdf> Acesso em: 24 set. 2020.

SANTOS, M. Por uma outra globalização: do pensamento único à consciência universal. 19. ed. Rio de Janeiro: Record, 2010.

SANTOS, M. O lugar e o cotidiano. In.: SANTOS, M. A natureza do espaço. São Paulo: Hucitec, 1996. p. 251-265.

SILVA, M. R. Juventudes e Ensino Médio: possibilidades diante das novas DCN. In.: AZEVEDO, J. C.; REIS, J. T. Reestruturação do Ensino Médio. São Paulo: Fundação Santillana, 2013. p. 65-80.

STECANELA, N.; WILLIAMSON, G. A educação básica e a pesquisa em sala de aula. Acta Scientiarum Education. Maringá, v.35, n. 2, p. 283-292, jul./dez. 2013. 
WENZEL, J. S. Ensinar a prática daPesquisa na FormaçãoInicial de Professores: uma vivência formativa. Revista Insignare Scientia. Chapecó/SC, vol. 2, n. 3, Edição Especial: Ciclos Formativos em Ensino de Ciências, 2019.

ZANON, L. B.; KIEREPKA, J. S. N. Problematização e reconhecimento de teorias e práticas de professores em formação para o ensino de Ciências com foco no educar pela pesquisa. Revista Insignare Scientia. Chapecó/SC, vol. 2, n. 1. jan./abr. 2019. 